\title{
ANALISIS SAHAM-SAHAM LQ45 UNUK MEMBENTUK PORTOFOLIO YANG OPTIMAL DENGAN MENGGUNAKAN SINGLE INDEX MODEL
}

\author{
Zul Azhar \\ Dosen Tetap Fakultas Ekonomi Universitas Pakuan
}

\begin{abstract}
ABSTRAK
Tujuan dari peneltian ini adalah untuk menentukan saham-saham LQ45 mana saja yang masuk dalam portofolio optimal dengan single index model dan menentukan nilai expected return dan standar deviasi portofolio optimal dengan menggunakan single index model. Pengolahan data dalam penelitian ini dilakukan secara statistik yang bersifat deskriptif. Kesimpulan dalam penelitian ini adalah untuk membantu dalam berinvestasi sebaiknya melakukan anallisis dengan single index model.
\end{abstract}

Kata kunci : Investasi, Investor, portofolio, risk. Single index model

The purpose of this research is to determine the 45 blue chip stocks which are included in the optimal portfolio with a single index models and determine the value of expected return and standard deviation of the optimal portfolio by using a single index models. The data in this study performed statistically descriptive. The conclusion of this study is to assist in investing should do anallisis with a single index models.

Keywords : Investment, Investor, portofolio, risk. Single index model

\section{Pendahuluan}

Salah satu analisis yang digunakan untuk oleh investor untuk mengurangi risiko berinvestasi adalah dengan membentuk Portofolio. Metode yang digunakan dalam membentuk portofolio optimal adalah dengan single index model.

Dalam nenanamkan dananya (investasi), seorang investor (baik individu maupun institusi) selalu dihadapkan pada return yang diharapkan dan tingkat risiko yang diterimanya. Dalam memilih jenis investasi seorang investor harus rasional. Rasionalitas investor dapat diukur sejauh mana berhasil memilih saham yang memberikan return maksimum pada tingkat risiko tertentu atau return tertentu pada risiko minimal (Setiawan, 2000: 15). Konsep ini sejalan dengan konsep yang dikemukakan harri Markowitz.
Adapun salah satu cara untuk menekan tingkat risiko adalah dengan membentuk portofolio, sebab dengan membentuk portofolio, risiko yang diterima investor dapat dihilangkan atau diperkecil. Dana yang diinvestasikan disebar pada surat berharga yang masuk dalam portofolio atau kita melakukan diversifikasi berbagai investasi. Hal ini sesuai dengan pepatah yang menyatakan "don't put all your eggs into one basket". Dengan membentuk portofolio, investor harus memilih berbagai kombinasi investasi yang sekiranya dapat saling menunjang dalam menstabilkan pendapatan dan memperkecil risiko. Hal ini dapat dilakukan juga dengan memilih investasi yang tingkat pendapatannya bergerak secara kontra siklikal satu sama lainnya atau berkorelasi negatif. 
Berdasarkan latar belakang tersebut di atas, maka tujuan dilakukannya penelitiannya ini adalah:

1. Menentukan saham-saham LQ45 yang masuk sebagai saham pilihan pada portofolio optimal dengan menggunakan single index model,

2. Menentukan expected return dan deviation standard return portofolio optimal dengan menggunakan single index model.

\section{Tinjauan Pustaka}

Return merupakan perubahan nilai atas dana yang diinvestasikan oleh investor. Keuntungan yang diharapkan dapat dinyatakan dalam persentase, hasil tersebut diperoleh dari perkembangan harga saham atau indeks harga saham individu (Ahmad, 2004: 104). Sedangkan risiko adalah penyimpangan terhadap hasil yang diharapkan. "The presence of risk means that more than one outcome is posibble (Bodie, Kane and Marcus, 2002: 154). Dalam melakukan investasi terdapat risikonya, jenis-jenis risiko yang diperhitungkan oleh seorang manajer investasi dalam memutuskan berinvestasi adalah risiko harga, risiko kelalaian, risiko inflasi, risiko nilai tukar, risiko reinvestasi, risiko ditarik kembali, dan risiko likuiditas (Fabozzi, 1999: 134).

Risiko dapat digolongkan atas risiko tidak sistematis (unsystematic risk) dan risiko sistematis (systematic risk). Dalam proses investasi terdiri dari dua bagian, bagian pertama adalah menaksir atribut-atribut risiko dan tingkat pengembalian yang diharapkan dari keseluruhan sarana investasi yang memungkinkan. Bagian kedua adalah formasi aktiva dari portofolio optimal, bentuk ini melibatkan determinasi terhadap peluang terbaik dari pengembalian ang berrisiko, tersedia berbagai kemungkinan investasi portofolio serta pemilihan portofolio terbaik dari investasi tersebut, (Bodie, Kane and Marcus, 2002: 209).

Pengertian single index model adalah suatu model regresi linier sederhana yang mengukur estimasi suatu aset dalam kaitannya dengan risiko. Return-return yang saling berhubungan karena return itu nenberikan respon terhadap perubahan pasar. (Elton and Gruber, 2003, 132133). Single index model mengasumsikan bahwa korelasi return antar sekuritas terjadi karena mereka bereaksi terhadap perubahan pada general market index. Menurut Elton dan Gruber (2003), asumsi dalam single index model disederhanakan sebagai berikut: 1). Nilai ekspektasi dari random error adalah nol, 2). Tidak ada korelasinya antara error dengan risiko pasar, 3). Error itu berdiri sendiri (independen).

Berikut disajikan expected return, variance dan covarian bila single index model digunakan untuk menunjukkan gerakan bersama saham-saham. Elton dan Gruber (2003) menyajikan sebagai berikut:

a. Expected return (mean return) : expected return on security is $E\left(R_{i}=E\left(\alpha_{i}+\beta_{i} R_{m}+e_{i}\right.\right.$

Since the expected value of the sum of random variabel is the sum of expected value, we have $E\left(R_{i}\right)=E\left(\alpha_{i}\right)+\left(\beta_{i} R_{M}\right)+E\left(e_{i}\right)$ $\alpha_{\mathrm{i}}$ and $\beta_{\mathrm{i}}$ are constant and by construction the expected value of $\mathrm{e}_{\mathrm{i}}$ is zero. Thus,

$$
E\left(R_{i}=E\left(\alpha_{i}+\beta_{i} \overline{R_{M}}\right.\right.
$$

b. Variance return:

The variance of the return on only security is

$$
\sigma_{i}^{2}=E\left(R_{i}-\bar{R}_{i}\right)^{2}
$$


Substitution for $\mathrm{R}_{\mathrm{i}}$ and $\bar{R}_{i}$ from the expression above yield

$$
\sigma_{i}^{2}=E\left(\left(\alpha_{i}+\beta_{i} R_{m}+e_{i}\right)-\left(R_{i}-\bar{R}_{i}\right)\right)^{2}
$$

Rearranging and noting that $\alpha$ 's cancel yield

$$
\sigma_{i}^{2}=E\left(\left(\beta_{i}-\left(R_{i}-\bar{R}_{i}\right)+e_{i}\right)^{2}\right.
$$

\section{Menentukan cut off rate}

Sequaring the term in the brackets yield

$\sigma_{i}^{2}=\beta_{i}^{2} E\left(R_{i}-\bar{R}_{M}\right)^{2}+2 \beta_{i} E\left[e_{i}\left(R_{M}-\bar{R}_{M}\right)\right]+E$

Recall that by assumption (or in some cases by construction)

$$
\begin{aligned}
& E\left[e_{i}\left(R_{M}-\bar{R}_{M}\right)\right]=0 \\
& \sigma_{i}^{2}=\beta_{i}^{2} E\left[e_{i}\left(R_{M}-\bar{R}_{M}\right)\right]+E\left(e_{i}\right)^{2} \\
& \sigma_{i}^{2}=\beta_{i}^{2} \sigma_{m}^{2}+\sigma_{M}^{2}
\end{aligned}
$$

c. Covariance return

The covariance between any two securities can be written as

$$
\sigma_{i j}=\left[\left(R_{i}-\bar{R}_{i}\right)\left(R_{J}-\bar{R}_{J}\right)\right]
$$

Substitution for $\mathrm{R}_{\mathrm{P}}, \bar{R}_{P}, \mathrm{R}_{\mathrm{i}}$ dan $\bar{R}_{i}$ yield

$$
\begin{aligned}
& \sigma_{I J}=\left[\left(\alpha_{i}+\beta_{i} R_{M}+e_{i}\right)-\left(\alpha_{i}+\beta_{i} \bar{R}_{M}\right)\right] *\left[\left(\alpha_{J}+\right.\right. \\
& \text { Simplifying for canceling the } \alpha \text { 's } \\
& \text { and combining the term involving } \\
& \beta \text { 's yields } \\
& \left.\sigma_{i j}=\left[\beta_{i}\left(R_{M}-\bar{R}_{M}\right)+e_{i}\right)\left(\beta_{J}\left(R_{m}-\bar{R}_{M}\right)+e_{J}\right)\right]
\end{aligned}
$$

Carrying out of mulplication

Setelah saham-saham disusun berdasarkan peringkat ERB, maka langkah selanjutnya ad (da) menentukan nilai Cut off Rate $\left(\mathrm{C}^{*}\right)$, dengan menggunakan rumus sebagai berikut:

$$
C_{i}=\frac{\sigma_{m}^{2} \sum_{j=1}^{i} \frac{\left(\bar{R}_{J}-R_{j}\right) \beta_{J}}{\sigma_{e j}}}{1+\sigma_{M}^{2} \sum_{J=1}^{i}\left(\frac{\beta_{J}^{2}}{\sigma_{e j}^{2}}\right.}
$$

3. Menentukan saham yang masuk dalam portofolio optimal

Langkah terakhir adalah menentukan proporsi masingmasing saham yang terpilih sebagai alokasi dana yang akan memberikan portofolio optimal,

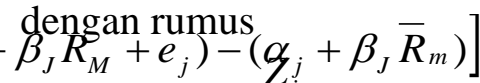

$$
X_{i}=\frac{Z_{i}}{\sum_{\text {included }} Z_{J}}
$$

Sedangkan nilai $\mathrm{Z}_{\mathrm{i}}$ dapat ditentukan dengan rumus

$$
Z_{i}=\frac{\beta_{i}}{\sigma_{e i}^{2}}\left(\frac{\bar{R}_{i}-R_{F}}{\beta_{i}}-C *\right)
$$

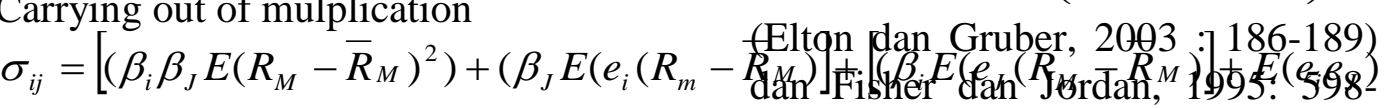
602)

Since the last three term are zero, by assumption

$$
\sigma_{i j}=\left[\beta_{i} \beta_{J} \sigma_{M}^{2}\right]
$$

Dalam pembentukan portofolio optimal dengan single index model, terdapat tiga langkah yaitu :

1. Memeringkat saham

Langkah pertama dalam pembentukkan portofolio optimal
Sedangkan yang dimaksud dengan expected return Portofolio adalah tingkat keuntungan yang lain adalah rata-rata tertimbang dari tingkat keuntungan yang diharapkan masing-masing saham yang membentuk portofolio tersebut, sedangkan varuabce return portofolio marupakan diharapkan dari portofolio tidak 
variabilitas risiko yang akan ditanggung oleh investor dalam melakukan investasi (Husnan, 1996: 54 - 60).

Standard deviasi return portofolio dapat digunakan untuk mengetahui perbedaan return nyata dari ekspektasi return. (Sharp et all, 1995: 178)

\section{Metode Penelitian}

Penelitian ini menggunakan data sekunder, data yang sudah dipublikasikan untuk umum yaitu data yang dikeluarkan oleh Bursa Efek Indonesia dan Bank Indonesia, Pengambilan data dilakukan secaranabual manual dokumen serta dengan menggunakan komputer (internet). Pengumpulan data dilakukan deengan studi pustaka di Bursa Efek Indonesia dan Bank Indonesia.

Penelitian ini termasuk penelitian deskriptif dengan studi kasus di PT. Bursa Efek Indonesia Jakarta. Penelitian ini dilakukan dengan menggunakan penelitian longitudinal, yaitu data diambil selama satu periode waktu tertentu, yaitu selama satu tahun. Variabel yang diamati adalah return saham individu, return pasar LQ 45, risiko saham, risiko pasar serta return aset bebas risiko.

Dalam penelitian ini, metode analisis yang dilakukan adalah pertama menentukan saham kandidat yang selanjutnya diolah untuk menentukan saham terpilih menjadi portofolio optimal dengan menggunakan single index model. Data yang digunakan adalah IHSI, IHSLQ45, dan suku bunga bank Indonesia. Pertama kita menentukan return saham individu dan return saham LQ45, selanjutnya return saham LQ 45 rata-rata. Selanjutnya dihitung nilai variance dan standar deviasi saham LQ45.
Return aset bebas risiko merupakan suku bunga sertifikat Bank Indonesia pada Bank Indonesia, ratarata suku bunga deposito berjangka satu bulan dihitumg dengan menjumlahkan SBI setiap bulan lalu dibagi dengan 12 .

Selanjut dilakukan penentuan portofolio optimal, yaitu langkah pertama menentukan ERB, semakin tinggi nilai ERB semakin besar peluang saham itu terpilih sebagai saham pembentuk portofolio optimal. Langkah kedua adalah menentukan nilai Cut off Rate $\left(\mathrm{C}^{*}\right)$, jika nilai ERB lebih besar dari nilai $C^{*}$ maka saham-saham itu masuk dalam portofolio optimal. Langkah ketika adalah menetukan prorsi masing-masing saham didalam portofolio optimal.

\section{Hasil dan Pembahasan}

Pada dasarnya seorang investor ingin mendapatkan return yang tinggi dengan risiko tertentu atau risiko yang rendah dengan return tertentu dari dana yang disebar dalam bentuk portofolio.

Sebelum menentukan ERB, langkah pertama yang dilakukan adalah menghitung selisih antara rata-rata return saham dengan rata-rata return aset bebas risiko $\quad\left(\bar{R}_{i}-\bar{R}_{F}\right)$.

Setelah dilakukan pemeringkatan saham berdasarkan rasio excess to beta (ERB), dari 42 saham kandidat ternyata 7 saham memiliki ERB negatif sehingga dikeluarkan menjadi saham terpilih, saham kandikat yang terpilih yang memiliki ERB positif berjumlah 25 saham, yaitu AALI, ANTM, ASII, BBCA, DNKS, GGRM, GJTL. HMSP, INCO, INKP, ISAT, JIHD, KLBF, MPPA, NISP, PNBN, PTBA, RALS, RMBA, SMCB, SMGR, TKIM, TLKM, TSPC, UNVR

Setalah diperoleh 25 saham yang memiliki ERB positif selanjutnya kita masuk dalam prosedur penentuan portofolio optimal dengan single index 
model. pertama yaitu mencari rasio excess to beta. Berikut adalah hasil

perhitungan ERB yang disajikan pada tabel

berikut:

Tabel 1

Daftar Saham kandidat Setelah Diperingkat Berdasarkan ERB

\begin{tabular}{|l|l|l|}
\hline No. & \multicolumn{1}{|c|}{ Saham } & \multicolumn{1}{c|}{ ERB } \\
\hline 1 & TKIM & 3.1317 \\
\hline 2 & SMGR & 2.7784 \\
\hline 3 & NISP & 2.7368 \\
\hline 4 & BBCA & 2.2904 \\
\hline 5 & AALI & 1.4840 \\
\hline 6 & ISAT & 1.1697 \\
\hline 7 & ASII & 1.0863 \\
\hline 8 & PTBA & 1.0411 \\
\hline 9 & PNBN & 0.9612 \\
\hline 10 & INKP & 0.9482 \\
\hline 11 & INCO & 0.8791 \\
\hline 12 & SMCB & 0.8148 \\
\hline 13 & TSPC & 0.7075 \\
\hline 14 & RMBA & 0.6352 \\
\hline 15 & TLKM & 0.4861 \\
\hline 16 & AMTM & 0.3645 \\
\hline 17 & GJTL & 0.3520 \\
\hline 18 & HMSP & 0.3488 \\
\hline 19 & MPPA & 0.2785 \\
\hline 20 & UNVR & 0.2421 \\
\hline 21 & JIHD & 0.2349 \\
\hline 22 & DNKS & 0.2170 \\
\hline 23 & KLBF & 0.1529 \\
\hline 24 & GGRM & 0.1468 \\
\hline 25 & RALS & 0.0389 \\
\hline & & \\
\hline
\end{tabular}

Data diolah dari tabel 4.3

Prosedur yang kedua dalam menentukan portofolio optimal dengan single index model adalah menentukan Cut off Rate $\left(\mathrm{C}^{*}\right)$. Dari nilai $\mathrm{C}^{*}$ sebagai prosedur penentuan saham terpilih dalam portofolio optimal diperoleh 15 saham yang masuk portofolio optimal yaitu AALI, ANTM, ASII, BBCA, INCO, INKP, ISAT, NISP, PNBN, PTBA, RMBA, SMCB, SMGR, TKIM, DAN TSPC. Untuk lebih jelasnya akan disajikan pada tabel do bawah ini; 
Tabel 2

Penentuan Saham Terpilih Kedalam Portofolio Optimal

\begin{tabular}{|l|l|l|l|l|}
\hline NO. & \multicolumn{1}{|c|}{ SAHAM } & \multicolumn{1}{c|}{$\mathbf{C}_{\mathbf{I}}$} & \multicolumn{1}{|c|}{ ERB } & \multicolumn{1}{c|}{ ERB - $\mathbf{C}_{\mathbf{I}}$} \\
\hline 1 & AALI & 0.07650607 & 1,484004 & 1.40749801 \\
\hline 2 & ANTM & 0.20348819 & $0 / 364454$ & 0.16096571 \\
\hline 3 & ASII & 0.35649978 & 1.0863 & 0.72980043 \\
\hline 4 & BBCA & 0.38661339 & 2.290401 & 1,90378747 \\
\hline 5 & INCO & 0.41291202 & 0.879106 & 0.46619358 \\
\hline 6 & INKP & 0.4590429 & 0.948178 & 0.48913544 \\
\hline 7 & ISAT & 0.53526633 & 1.169733 & 0.63446657 \\
\hline 8 & NISP & 0.49941605 & 2.736835 & 2.23748727 \\
\hline 9 & PNBN & 0.51989603 & 0.961208 & 0.44131179 \\
\hline 10 & PTBA & 0.55141878 & 1.041147 & 0.4897278 \\
\hline 11 & RMBA & 0.53198217 & 0.635175 & 0.10391935 \\
\hline 12 & SMCB & $0 / 57781604$ & 0.814896 & 0.23707951 \\
\hline 13 & SMGR & 0.59915125 & $2 / 778403$ & 2.179251591 \\
\hline 14 & TKIM & 0.6659859 & 3.131691 & 2.465705369 \\
\hline 15 & TEPS & 0.66068111 & 0.705702 & 0.045020513 \\
\hline
\end{tabular}

Sumber : diambil dan diolah dari tabel 46 dan 47

Prosedur yang ketiga penentuan portofolio optimal dengan single index model adalah menentukan proporsi dana yang akan diinvestasikan pada sahamsaham terpilih. Hasil perhitungan proporsi dana $\left(\mathrm{Z}_{\mathrm{i}}\right)$ adalah saham yang memiliki proporsi terbesar adalah saham TKIM dengan proporsi dana sebesar 17.249\%, SMGR dengan proporsi dana sebesar $15.111 \%$, NISP dengan proporsi dana sebesar $13.251 \%$, ASII dengan proporsi dana sebesar 9.281\%, AALI dengan proporsi dana sebesar $7.758 \%$, ISAT dengan proporsi dana sebesar $6.612 \%$, BBCA dengan proporsi dana sebesar $6.090 \%$, INKP dengan [roporsi dana sebesar $4.996 \%$, PTBA dengan proporsi dana sebesar $4.923 \%$, PNBN dengan proporsi dana sebesar $4.906 \%$, INCO dengan proporsi dana sebesar $3.852 \%$, SMCB dengan proporsi dana sebesar $2.610 \%$, ANTTM dengan proporsi dana sebesar $2.042 \%$, RMBA dengan proporsi dana sebesar $0.902 \%$ dan terakhir TSPC dengan proporsi dana sebesar $0.419 \%$. hal ini nebunjukkan bahwa proporsi yang akan dialokasikan pada saham-saham dari total investasi sebesar nilai $\mathrm{X}_{\mathrm{i}}$.

Langkah selanjutnya adalah menghitung nilai expected return portofolio. Setelah diambil dan diolah dari tabel 4.9 dan lampiran II dan IV, maka diperoleh nilainya yaitu sebesar 1.77362792 atau 177. 3628\%. Artinya jika investor menginvestasikan dananya ke-15 saham tersebut di atas sesuai dengan proporsi masing-masing akan diperoleh return portofolio sebesar 1.77362792 atau $177.36 \%$ perminggu dari dana yang diinvestasikan. Nilai tersebut tidak memiliki ujuran standar tertentu dan apabila ingin mengetahui tingkat kebaikannya maka haruslah dibandingkan dengan model portofolio yang lain.

Sedangkan perhitungan nilai variance dari ke-15 saham yang dinvestasikan dari seluruh kombinasi yang ada adalah 6.73439. dengan telah diperolehnya nilai variance, maka langkah selanjutnya adalah menghitung nilai standar deviasi yaitu dengan mengakarkan nilai variance tersebut, 
sehingga diperoleh hasil satandar deviasi sebesar 2.59507.

Hal ini berarti telah terjadi penyimpangan dari nilai yang diharapkan (return) atas penanaman dana (investasi) yang dilakukan pada saham-saham yang masuk dalam fortofolio optimal sebesar 6.73439 dengan standar deviasi sebesar $259.507 \%$.

\section{Penutup}

Dari penelitian diperoleh hasil sebagai berikut; pada prosedur pertama dalam menentukan portofolio optimal dengan single index model adalah menentuka ERB. Dari 32 saham yang dihitung ERBnya terdapat 25 saham yang memiliki ERB positif sebagai kandidat saham yang masuk kedalam portfolio optimal yaitu AALI, ANTM, ASII, BBCA, DNKS, GGRM, GJTL, HMSP, INCO, INKP, ISAT, JIHD, KLBF, MPPA, NISP. PNBN, PTBA, RALS, RMBA, SMCB, SMGR, TKIM, TLKM, TSPC dab UNVR. Prosedur kedua adalah menentukan nilai Cut-off Rate $\left(C^{*}\right)$, bertujuan untuk memisahkan atau memilih saham-saham yang masuk dalam portfolio optimal dengan membandingkan dengan nilai ERB jika hasilnya positif itulah yang masuk dalam portofolio optimal. Setelah dihitung diperoleh 15 saham yang masuk dalam portofolio optimal yaitu AALI, ANTM, ASII, BBCA, INCO, INKP, ISAT, NISP, PNBN, RMBA, SMCB, SMGR, TKIM DAN TSPC. Prosedur yang ketiga adalah menentukan proporsi dana yang akan dialokasikan ke-15 saham tersebut, setelah diolah dan dihitung diperoleh proporsi dana sebagai berikut AALI = $7.7576 \%$, ANTM $=2.0416 \%$, ASII $=$ $9.2087 \%, \mathrm{BBCA}=6.6900 \%, \mathrm{INCO}=$ $3.8518 \%$, INKP $=4.9964 \%$, ISAT $=$ $6.6121 \%$, NISP $=13.2512 \%$, PNBN $=$ $4.9058 \%, \mathrm{PTBA}=4.9226 \%, \mathrm{RMBA}=$
$0.9018 \%, \mathrm{SMCB}=2.6097 \%, \mathrm{SMGR}=$ $15.110 \%$, TKIM $=17.2492 \%$ dan TSPC $=0.4190 \%$. Setelah diketahui proporsi dana yang diinvestasikan pada sahamsaham yang masuk portofolio optimal, maka selanjutnya dihitung expected return portofolio sebesar 1.7736379 perminggu dan variance serta standar deviasi portofolio sebesar masingmasing 6.73439 dan 2.59507. Setelah pembahasan ini penulis menyarankan kepada para investor dalam berinvestasi untuk lebih selektif agar memperoleh return yang optimal dengan risiko tertentu atau return tertentu dengan risiko minimal. Untuk membantu dalam berinvestasi sebaiknya melakukan anallisis dengan single index model.

\section{DAFTAR PUSTAKA}

http" www.idx. Co, id, Bursa Efek Indonesia

www.bapepam.go.id , Badan Pengawas pasar Modal

Bank Indonesia

Ahmad, Komarudin, 2004, Dasar-dasar Manajemen Investasi dan Portofolio, Edisi Revisi, PT. Rineka Cipta Jakarta.

Bodie, Zvi, Alex Kane and Alan J. Marcus, 2002, Investment, Fifth Edition, Mc Graw Hill Financial Series.

Black, StanleyB and Geoffrey A, Hort, 1997, Foundation ofFinancial Management, Fourth Edition, Richard D. Irvin Inc.

Eales, Brian A, 1995 Financial Risk Management, Mc Graw Hill Book Co, Europe

Elton, J Martin, and Martin J. Gruber, 2003, Modern Portfolio Theory and Investment Analysis, Six Edition , John \& Wiley \& Sons Inc. 
Fabozzi, Frank, 1999, Manajemen Investasi, Salemba Empat.

Fisher, Donald E, and Ronald J. Jordan, 1995, Security Analysis and Portfolio Management, Six Edition, Frentice Hall, New Jersey.

Husnan, Suad, 2001, Dasar-dasat Teori Portofolio dan Analisis Sekuritas, Edisi 3, Yogyakarta: UPP AMP YKPN.

Reily, Frank K, and Keith C. Brown, 1997, Investment Analysis and Portfolio Management, Fifh Edition, The Dryden Press.

Setiawan, Heru, 2004, Analisis Investasi Dalam Menentukan Portofolio Optimal Di Bursa Efek Jakarta, Trikonomika Jurnal Ekonomi, Volume 1, Nomer 1 Bandung

Sharpe, William F,.Gordon J. Alexander and Jeffrey V. Baiiley, 1995, Investment, Fifth Edition, Frentice Hall Englewood Cliffts, New Jersey. 